\title{
O Grupo Escolar Coronel Júlio César de Itatiba (SP): conexões entre a história da educação, o processo de restauração do prédio e a cidade
}

\section{The Coronel Júlio César de Itatiba (SP) School Group: connections between the history of education, the building restoration process and the city}

\author{
Andreia Cristina Borges Rela Zattoni ${ }^{1 *}$, Maria de Fátima Guimarães ${ }^{1}$, Daniel Amaro Cirino \\ Medeiros ${ }^{1}$
}

\section{RESUMO}

Neste artigo, propomos conexões entre aspectos da trajetória da cidade de Itatiba (SP), a história da educação brasileira, a criação do primeiro grupo escolar de Itatiba (1896) e o processo de tombamento e restauração do prédio que pertenceu ao então Grupo Escolar Coronel Júlio César. Para tanto, em um primeiro movimento, abordamos as transformações que ocorreram no contexto sociocultural, no período de 1850 a 1920, no qual observou-se a rápida expansão cafeeira de Itatiba no imbricamento da emergência da temática da educação enquanto uma questão a ser enfrentada para se garantir o progresso local. Após, seguimos em direção a história dos grupos escolares no período, mobilizando intencionalidades republicanas que orientaram os projetos arquitetônicos de tais escolas; na sequência trazemos a história de criação do Grupo Escolar Coronel Júlio César e abordamos seu projeto de tombamento e restauração, quando da proximidade de seu centenário. E, por fim, apresentamos nas considerações finais. que os grupos escolares podem ser considerados como templo do saber da modernidade e tal projeto avançou pelo século afora considerados de excelência até a atualidade.

Palavras-chave: Grupo Escolar Coronel Julio Cesar; Itatiba; Projetos arquitetônicos.

ABSTRACT

In this article, we propose connections between aspects of the trajectory of the city of Itatiba (SP), the history of Brazilian education, the creation of the first school group in Itatiba (1896) and the process of listing and restoration of the building that belonged to the then Grupo Escolar Coronel Julio Cesar. For that, in a first movement, we approach the transformations that took place in the sociocultural context, in the period from 1850 to 1920, in which the rapid expansion of coffee in Itatiba was observed in the imbrication of the emergence of the theme of education as an issue to be faced for ensure local progress. Afterwards,

\footnotetext{
${ }^{1}$ Universidade São Francisco

*andreia.zattoni@usf.edu.br
} 
we continue towards the history of school groups in the period, mobilizing republican intentions that guided the architectural projects of such schools; Next, we bring the creation story of Grupo Escolar Coronel Júlio César and discuss its listing and restoration project, as it approaches its centenary. And, finally, we present in the final considerations. that school groups can be considered as a temple of knowledge of modernity and this project has advanced throughout the century, considered of excellence until today.

Keywords: Coronel Julio Cesar School Group; Itatiba; Architectural Projects.

\section{1- Um pouco da trajetória da cidade de Itatiba}

A cidade de Itatiba é um município do estado de São Paulo e faz parte da Região Metropolitana de Campinas.

Tem sua origem em um povoado às margens do Rio Atibaia, entre os anos de 1804 e 1805. Gabuardi (2004) e Navarra (1977), destacam que os primitivos habitantes eram fugitivos das prisões das vilas de Atibaia e Santo Antonio da Cachoeira (atual cidade de Piracaia).

De acordo com p Almanach de Itatiba (1916, p. 24), tal origem se dá com "corrente interessada de imigração [...]. Os denominados "gente de Lourenço Leme". Eles fundaram os bairros dos Pereiras, José Pereira, e dos Coutos. No dia 9 de dezembro de 1830, por intermédio do Decreto Imperial deu-se a criação da Freguesia de Nossa Senhora do Belém, na denominada Vila de Jundiaí. Nos períodos de 1810 a 1830 é noticiado o crescente número de moradores, o aumento econômico da região e a constituição de uma capela que incentivava o poder local a solicitar o nome de Freguesia, que ocorreu em 1830. Em 20 de fevereiro de 1857, foi promulgada a Lei Estadual n 553, pela Assembleia Legislativa da Província de São Paulo, que abrange a Freguesia à Vila Nossa Senhora de Belém de Jundiaí. Belém de Jundiaí que por 18 anos permaneceu subordinada à Vila de Jundiaí. Ocorreu a conquista da independência econômica de Jundiaí na Cidade de Nossa Senhora de Belém de Jundiaí, em 16 de março de 1876. É plausível notar nas fontes a referência ao aumento da produção agrícola e ao desenvolvimento econômico da cidade. Camargo (JORNAL DE ITATIBA, 2003, p. 15) destaca que toda a riqueza não foi difundida igualitariamente, mas aglomerada sob os comandos dos "Barões do Café". 
Ocorreram novas demandas sociais acompanhadas pelo crescimento da vila e com isso as condições para que incidisse a criação de instituições e execução de obras ordenava com isso a incidência de manobras políticas. Marques (2008) destaca que ocorreu na sequência a necessidade da alteração do nome da cidade, pois a denominação "Bethlém de Jundiahy" conotaria que a cidade ainda possui pertencimento a Jundiaí. De acordo com o Almanach de Itatiba (1916, p. 33),

Por lei provincial n. 18 de 16 de Março de 1876 a Vila de Belém de Jundiahy foi elevada à categoria de cidade com a mesma denominação até que pela lei n. 80 de 3 de abril de 1877 passou a cidade denominar-se Itatiba, a pedido da Câmara Municipal que alegava a possibilidade de se confundir a primitiva denominação com outras semelhantes que existiam na Província.

Camargo (JORNAL DE ITATIBA, 2003, p. 15) acrescenta que, a cidade recebe o nome de Itatiba, que em tupi significa grande quantidade de pedra, em em 8 de maio de 1877, por requerimento dos vereadores na Assembleia Legislativa da província, pela Lei Provincial $n^{\circ} 36$.

Salienta-se que no período Itatiba experimentou um vertiginoso crescimento populacional que, de 6.000 passa no período para 23.000. Navarra (1977, p. 19), afirma que "Em 1874, aproximadamente um terço da população de Itatiba era constituída de escravos, percentagem só encontrada em Campinas, enquanto as demais áreas vizinhas apresentavam percentagens bem menores", o que acaba por ser uma das singularidades da história local na relação com municípios circunvizinhos.

\subsection{A Instrucção como parte do progresso}

Dentre os melhoramentos e progresso apregoados pelos periódicos locais, a preocupação com a escola e a necessidade de urbanização da cidade, eram temáticas extremamente valorizadas. Em 13 de maio de 1896 são inauguradas as escolas reunidas de Itatiba. No período, as escolas reunidas funcionavam em casas alugadas pela 
administração municipal. No Almanak de Itatiba (1905) localizamos a identificação dessas escolas municipais e de seus respectivos professores:

\author{
Bairro de Santa Cruz \\ Professor - Secundino Veiga, organizador deste livro, rua Rangel \\ Pestana. \\ Conceição de Barra Mansa \\ Sexo masculino. Professor, Antonio Marcondes Alves Alvim. \\ Sexo feminino. Professora, d. Constança Brazilia Alvim; adjunta, d. \\ Eliza de Castro Ferraz. \\ Bairro do Feital \\ Professor - Benedicto Martins. \\ [...] \\ Inspector municipal \\ Tte. Coronel José de Paula Andrade, rua Campos Salles. Sendo de 20 o \\ número de cadeiras neste município, faltam ainda 10 para serem \\ providas.
}

Itatiba contava com escolas elementares privadas, situadas na área central da cidade (ALMANACH DE ITATIBA, 1905). No começo do século XX é possível perceber uma maior preocupação com os assuntos relacionados à educação nos periódicos locais - o tema passa a ser vinculado à condição obrigatória para se garantir o progresso da cidade. Como observa-se no jornal Gazeta de Itatiba (01/03/1904), na seção "Instrução", é ressaltada a necessidade da educação:

\begin{abstract}
A alma humana sem educação, é bem semelhante ao mármore bruto, que não mostra as belezas que lhe são inherentes, enquanto a mão artística do homem esculptor não torna a sua superfície polida e não descobre as belezas que o ornam e os veios que o matizam. Do mesmo modo, a educação sobre uma alma nobre faz aparecer as virtudes e perfeições nelas latentes que, sem o seu auxílio, jamais poderiam aparecer. O grande Aristóteles, autorizadamente disse: - a estátua está oculta no mármore bruto, o escultor apenas tira a matéria supérflua. A educação é para a alma o que a estética escultura é para o bruto mármore.
\end{abstract}

A educação é assim compreendida, na época, como o elemento capaz de formar a pessoa, moldar, modelar, como um escultor faz com uma pedra de mármore. Nesse mesmo jornal, na seção "Grupos Escolares", explica-se a importância dos grupos, associando-os ao projeto de crescimento, de progresso da cidade: 
O patriotico Governo do nosso portentoso estado de S. Paulo, interpretando com toda lógica a importância da instrução infantil, não tem descuidado deste sublime objeto. Em todos os lugares mais considerados tem ele feito disseminar a deslumbrante luz da instrução, por meio de estabelecimentos denominados grupos escolares. Esta importantíssima instituição que imortalizou o emérito Dr. Cesário Motta, tem formado, forma e formará alicerces tão sólidos como os de granito, sobre os quaes se há de erigir sumptuosa e fulgurante a auspiciosa sociedade paulistana do porvir (GAZETA DE ITATIBA, 01/03/1904).

A seção continua com considerações acerca da estrutura administrativa dos grupos escolares:

O corpo docente dessas casas de instrução é constituído por um diretor e outros professores, que são seus adjuntos, dos quais depende o crédito intelectual e moral desses estabelecimentos.

[...] um bom corpo docente faz o bom grupo escolar; porque, embora o director seja apto, inteligente e enérgico, nada poderá fazer em prol do crédito do grupo que dirige, se não for rodeado de auxiliares que secundem seus esforços, sua boa vontade e seu empenho em cumprimento de seus deveres (GAZETA DE ITATIBA, 01/03/1904).

Nesse discurso é possível flagrar o momento em que a figura hierárquica do diretor emerge como o responsável pela organização escolar na relação com os demais membros do corpo docente. $\mathrm{O}$ diretor e professor deveriam cumprir suas atribuições previstas no "Regulamento da Instrução Pública", zelando pela "Santa Causa da Instrução Paulista" (GAZETA DE ITATIBA, 08/03/1904).

Conforme a seção "Instrução" do jornal Gazeta de Itatiba (08/03/1904), a educação deveria começar no ambiente familiar, aos cuidados da mulher, que deveria pautar sua conduta na religião católica, mesmo o Estado tendo se tornado leigo.

Por um princípio de conexidade a educação é para a instrução o que esta é para aquela. Para obter-se, porém, uma instrução correspondente à aspiração dos espíritos adiantados e progressistas, é mister: primeiro que toda uma boa educação doméstica sob os moldes da moral, depois 
um pessoal docente digno de todo conceito, um professorado enfim que seja honesto, dotado de toda moralidade, e que se imponha pelas suas virtudes cívicas, como levitas do bem, e por último a intervenção do governo, visto como a instrucção deve ser, indubitavelmente, uma de suas preocupações, como um ramo de serviço, de onde emana a prosperidade do povo. Na escolha do professor, quando entrar em jogo a competência e capacidade para ensinar, deve o governo pôr de parte a intervenção política que tudo aniquila, corrompe e estraga, dando somente valor a quem dispuser do grão de saber necessário e de ilibada reputação de moralidade, comprovada por actos não só da vida pública como também da vida privada.

Itatiba, - 1904.

Pestalozzine.

No artigo, a educação é associada ao progresso, à "prosperidade do povo", e teria como pressuposto que os professores deveriam ter uma moral ilibada e uma postura cívica também. Ali sobressai ainda um alerta, quase uma denuncia, no momento em que seu autor preconiza que o governo não pode pautar a indicação dos professores a partir de intervenção política. Tal fato sugere que isso ocorria com frequência e seria motivo de descontentamento e tensão local.

Nesse sentido, propomos que a modernização urbana pela qual passaram algumas cidades no período, sobretudo no sudeste - e Itatiba não foi uma exceção; e a adoção e disseminação dos grupos escolares e de seu método de ensino intuitivo - pautado na educação dos sentidos, marcado por uma racionalidade produtiva do tempo, vão ao encontro do projeto político republicano, que seguia no rastro do avanço da modernidade (SEVCENKO, 1998)

A partir da criação do Grupo Escolar Coronel Júlio César, os jornais, e os almanaques locais passam a ceder espaços para a publicação de notas e artigos sobre a educação de uma forma geral, sobre o grupo escolar e as escolas particulares que haviam em Itatiba, informando sobre a rotina escolar de diretores e professores, sobre visitas recebidas, sobre matrículas e festejos, dentre outras notícias. Há um direcionamento, pelos periódicos locais, das atenções dos leitores para a necessidade de instrução e alfabetização, na perspectiva de que ambas garantiriam ascensão e distinção sociais. 


\begin{abstract}
A instrucção rural
A ninguém é dado avaliar os altos benefícios que trazem ao nosso país escolas rurais, raramente providas devido às sérias dificuldades que lutam os professores encarregados de tão nobre missão, nesses centros onde a vida é um difícil problema. A população agrícola de nosso país, é, em sua maioria completamente ignorante, alheia em sua maioria aos preceitos de sociabilidade.

As câmaras municipais, devem como a nossa, espalhar a instrução popular nesses centros, onde só reina a indolência, tendo como companheira inseparável a miséria com todos seus horrores. É' uma calamidade o que se nota em nossos bairros rurais: crianças em o mais triste estado de ignorância, entregues a mais desordenada indolência percorrendo as propriedades mais abastadas em busca de um pedaço de pão, unicamente porque seus genitores vivem preocupados com os tradicionais mutirões, educação herdada de seus antepassados.[...] Oxalá, que às câmaras municipais, tratem deste problema com o necessário interesse, fazendo de suas escolas, um foco de luz e progresso (A REACÇÃO, 26/02/1911).
\end{abstract}

$\mathrm{O}$ artigo anterior traz marcas de um preconceito que começou a ganhar maior vigor com a urbanização crescente do estado de São Paulo, a ideia de que no campo reinava a indolência exclui de visibilidade e valorização todo o trabalho necessário para garantir o cultivo e exploração da terra e o cuidado dos rebanhos, para além do que, revela que havia uma população rural, em particular formada por crianças, que passava fome justamente em um momento em que os periódicos locais preconizavam e comemoravam o progresso de Itatiba. Esse artigo desvela as contradições do período. Ainda, quando seu autor denuncia a permanência dos mutirões nas relações de trabalho rural, ele flagra uma organização de trabalho que não se fia pelo salário e racionalidades fabris, algo instigante de se pensar, posto que naquele momento a exploração do café nas fazendas de Itatiba estava no auge, de acordo com os periódicos pesquisados, e a produção cafeeira, nas primeiras décadas do século XX, já havia incorporado muito da racionalidade capitalista na administração de seus recursos e trabalhadores. Logo, diante do prelúdio republicano, do desejo de progresso, "[...] o passado, as tradições, os grupos populares e todos os sinais da sua presença se tornaram fontes de vergonha, mal-estar e indignação, manchas que conspurcavam a ordem e o progresso" (SEVCENKO, 1998, p. 31).

Para além do que, o artigo alerta o leitor mais atento para o fato de que, muitas famílias da zona rural, não tinham ainda apreço pela educação escolar. Esta, que com os grupos escolares passará a impor rigidamente às famílias um calendário escolar e um horário de aulas que nem sempre seguiam ao encontro dos afazeres e colheitas rurais, para 
os quais o trabalho infantil era necessário. Os tempos e os espaços escolares no processo de institucionalização da escola primária no Brasil (FARIA FILHO; VIDAL; 2000) A educação escolar foi vista como a solução de muitos problemas nacionais, mas ela não foi garantida aos diferentes segmentos sociais.

\section{2- Os Grupos Escolares: dos projetos pilotos às intencionalidades republicanas e disputas locais, à luz de ideais da modernidade}

Ao estudar a história dos grupos escolares no Brasil, em particular no Estado de São Paulo, entre fins do século XIX e primeira década do século XX, nos deparamos com uma arquitetura cuja linguagem traz marcas características de valores estéticos da época, valorizados por uma dada concepção de civilização e progresso.

Os grupos projetados nas cidades de Bragança Paulista, Taubaté, Jaú, Mogi das Cruzes, Pindamonhangaba, Caçapava, São Simão, Santa Bárbara, Cajuru e muitos outros, entre estes o grupo escolar Coronel Júlio César, de Itatiba, possuem projetos arquitetônicos semelhantes e foram projetados sob a responsabilidade de José Van Humbeeck, o arquiteto com mais extensa produção na antiga Superintendência de Obras Públicas (CORRÊA, NEVES; MELLO, 1991). Segundo Corrêa, Neves e Mello (1991), as fachadas das escolas projetadas por José Van Humbeeck possuem características muito semelhantes, destacando-se pela simplicidade estilística formal do neoclássico.

José Van Humbeeck destaca-se também como autor dos primeiros projetos para grupos escolares de um único pavimento.com todos os corredores abertos, possibilitando visualizar a circulação de pessoas no interior do prédio, bem como o que acontecia no transcorrer do período letivo. Os engenheiros Francisco Homem de Mello e Pedro Soares de Camargo foram os responsáveis pela obra do Grupo Escolar de Itatiba (ALMANACH DE ITATIBA, 1916). Vários outros prédios construídos então pelo governo estadual, em diferentes cidades paulistas, seguiram o mesmo estilo arquitetônico - eclético, com elementos neogóticos e neoclássicos (OLIVEIRA, 2007). Outro aspecto a ser destacado é que, naquele contexto sociocultural, 
A racionalização burocrática - divisão do tempo e do trabalho escolares - e a gestão racional do espaço coletivo e individual fazem da escola um lugar em que adquirem importância especial a localização e a posição, o deslocamento e o encontro dos corpos, assim como o ritual e o simbólico (VIÑAO FRAGO; ESCOLANO, 2001, p. 80).

A decisão de instalar uma escola em determinado logradouro e não em outro seguia em direção as preocupações com: as condições higiênicas, climáticas, topográficas, de ventilação, de iluminação, de localização central do terreno escolhido; sendo assim, a arquitetura cumpriu outra função, além de abrigar salas de aula, contribuiu com a implementação de uma racionalidade escolar que seguia ao encontro da implementação de uma educação seriada e o disciplinamento dos corpos. O modelo escolar dos grupos escolares impôs o agrupamento de classes isoladas num único prédio escolar, formando-se classes de acordo com a idade e nível de aprendizagem.

\section{1- O Grupo Escolar de Itatiba: Coronel Júlio César}

A criação do primeiro Grupo Escolar de Itatiba se deu em 1896. Neste ano haviam vinte e seis grupos escolares em funcionamento no estado e mais sete em via de instalação (VENDRAMIN, 2009). A cafeicultura trouxe o desenvolvimento para Itatiba, plantado em larga escala nas fazendas locais. Dentre os fazendeiros mais empenhados na construção do grupo escolar em Itatiba temos o Coronel Júlio César de Cerqueira Leite, chefe do Partido Republicano local, que tinha grande prestígio junto a seu conterrâneo campineiro Manuel Ferraz de Campos Salles, presidente da Província de São Paulo, e que viria a ser presidente do Brasil.

A amizade política com o republicano Campos Salles facilitou-lhe a criação do primeiro Grupo Escolar em Itatiba (SANGIORGI, 1969), por meio do Decreto Estadual $\mathrm{n}^{\circ} 218$, de 28 de julho de 1894. Contudo, tal iniciativa contou também com a interferência de outro político influente, o senador estadual Antônio de Lacerda Franco (Partido Republicano Paulista - PRP, eleito pela primeira vez em 1892), o qual garantiu que Itatiba fosse incluída entre as cidades do interior que seriam beneficiadas pelo presidente do 
Estado de São Paulo, Campos Sales (PRP, 1896-1897), com a construção de um Grupo Escolar.

Para Souza (1998, p. 93),

Motivações políticas podem ser apontadas como justificativas para a criação dos grupos escolares em determinadas localidades. Evidentemente, a legislação previa a concessão de prioridade às localidades que contribuíssem com terrenos e donativos para a instalação das escolas. No entanto, a autorização do Conselho Superior, tendo em vista os critérios de prioridade, era subestimado, uma vez que a determinação da criação de escola constituía um ato do governo.

A instalação do Grupo data de $1^{\circ}$ de julho de 1896 e que a Lei ou Decreto de sua fundação foi publicado no Diário Oficial de 13 de maio de 1896. Sua denominação inicial foi "Grupo Escolar Coronel Júlio César"2 (13/05/1896), posteriormente, com a extinção dos grupos escolares passou a denominar-se "E.E.P.G. 'Coronel Júlio César”, de acordo com a resolução da Secretaria Estadual n 23/76, de 27 de janeiro de $1976^{3}$, publicada em 28/01/1976.

No Almanach de 1905 encontramos referenciais ao Grupo Escolar informando que ele funcionava desde treze de maio de 1896 e que tinha por volta de quatrocentos alunos de ambos os sexos matriculados.

O novo edifício do primeiro Grupo Escolar de Itatiba foi construído na rua Rangel Pestana, situada na trama urbana central da cidade; ficando próximo da atual Praça José Bonifácio (antigo Largo da Cadeia, Praça da Câmara Municipal), da Igreja Matriz, a

\footnotetext{
2 Júlio César nasceu em 1845 na Fazenda Pau d'Alho, em Campinas. Era irmão do general Francisco Glicério, que liderava o Partido Republicano Federal (PRF) e dava apoio a Floriano Peixoto. Partido que apoiava uma política industrialista. Já o Partido Republicano Paulista (PRP), corrente política formada por agricultores, era liderado por Jorge Tibiriçá, que apoiava Campos Sales, defendendo nesse período, o ponto de vista mais conservador (MEDEIROS, 2013). Júlio César fundou e liderou o PRF em Itatiba até 1897. Quando houve a cisão no Partido Republicano Federal. A presidência do partido local foi substituída por Francisco Rodrigues Barbosa, que se tornou seu rival. Júlio César de Cerqueira Leite faleceu no dia 2 de maio de 1922, na cidade de Campinas.
}

${ }^{3}$ Gestão do governador do estado Paulo Egydio Martins. 
localização privilegiada do grupo denotava mais um elemento que o caracterizava como fruto do projeto republicano. Buffa (2002) e Pinto (2002, p. 43-44) pontuam que a escolha dos terrenos era criteriosa: “[...] quadras inteiras ou grandes lotes de esquina que proporcionassem uma visualização completa do edifício e permitisse múltiplos acessos”. Os terrenos onde foram implantados os grupos escolares localizavam-se "[...] em regiões nobres, esses edifícios marcam, definitivamente, pela imponência e localização, seu significado no tecido urbano".

A pedra fundamental do Grupo Escolar foi colocada em 30 de dezembro de 1906, e os engenheiros Pedro Soares de Camargo e Francisco Homem de Mello, foram contratados para construir o edifício, que foi concluído em 1908 (ALMANACH DE ITATIBA, 1916, p. 59). Nesse período, estava na presidência do estado Jorge Tibiriçá (1904-1908), que pertencia ao PRP. O prédio mereceu elogios da imprensa itatibense em diferentes notícias publicadas no período.

Os grupos escolares perpetuaram uma memória dos republicanos, que foi disseminada pela imprensa da época, ligada a eles, a exemplo do Almanach de 1916, que afirmava a excelência da República e sua superioridade frente à monarquia, em decorrência do modelo educacional criado com os grupos escolares. Estes deram visibilidade à República e eram tomados como signos do progresso e da modernidade, pelos republicanos.

Sob tal perspectiva, concordamos com Escolano (2001, p. 28) quando nos propõe que:

Não apenas o espaço-escola, mas também sua localização, a disposição dele na trama urbana dos povoados e cidades, têm de ser examinada como um elemento curricular. A produção do espaço escolar no tecido de um espaço urbano determinado pode gerar uma imagem da escola como centro de um urbanismo racionalmente planificado ou como uma instituição marginal e excrescente.

E, endossamos quando o mesmo autor (2001, p. 30) afirma que a cidade: 
[...] é um constructo gestado entre interesses e conflitos, apesar do qual o entremeado de racionalidades e irracionalidades em que ela se materializa constitui uma parte importante, decisiva, do currículo não cursado, uma fonte silenciosa de ensinamentos.

\section{Cumpre lembrar ainda que}

Uma vez que a organização dos grupos escolares estabelecia a reunião de várias escolas primárias de uma determinada área em um único prédio, a administração pública entendeu ser um benefício financeiro aos seus cofres o fato de não ter que arcar com os aluguéis das diversas casas que abrigavam as escolas isoladas. (BENCOSTA, 1996, p.70)

A data de inauguração oficial do Grupo Escolar foi 21 de abril de 1909. Em sessão solene, com a presença do diretor, corpo docente e alunos, foi formalizada a inauguração. Em seguida, houve uma festa literária e musical da qual estes participaram.

A imagem do Grupo Escolar Coronel Júlio César estampada na página do Almanach de 1916, é apresentada a seguir. A imagem visual destaca a imponência arquitetônica do prédio na relação com o entorno e as janelas amplas e simétricas em grande número, características arquitetônicas destinadas a garantir a iluminação e ventilação. Como destaca Carvalho (2003), os edifícios dos grupos escolares tinham que ser amplos, bem iluminados, com materiais escolares em profusão e inéditos, evidenciando todo o progresso que a nova ordem política instaurava, ou seja que os republicanos desejavam. Observando a imagem, percebe-se, pela construção do muro, que o grupo pesquisado foi construído num terreno íngreme, tanto quanto que na proporção com o tamanho da pessoa que caminha pela calçada lateral, pode-se considerar as dimensões do prédio e sua volumetria, para aquela época, eram monumentais. 
Figura 1 - Imagem do Grupo Escolar no Almanach de Itatiba, 1916

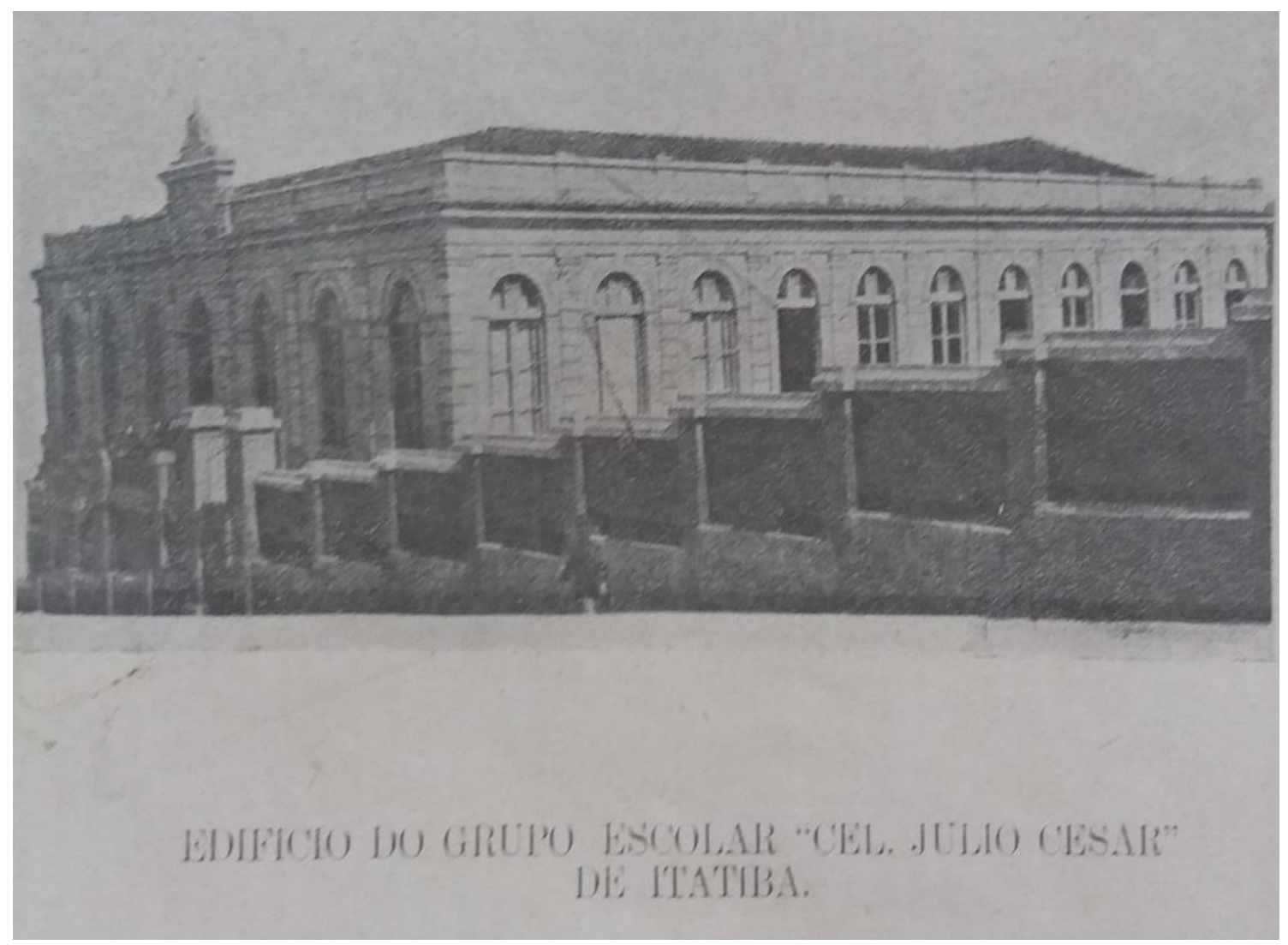

Fonte: Almanach de Itatiba, 1916, p. 57.

A par de tais observações, destaca-se que de acordo com Escolano (2001, p. 26)

A arquitetura escolar é também por si mesma um programa, uma espécie de discurso que institui na sua materialidade um sistema de valores, como os de ordem, disciplina, e vigilância, marcos para a aprendizagem sensorial e motora e toda uma semiologia que cobre diferentes símbolos estéticos, culturais e também ideológicos. Ao mesmo tempo, o espaço educativo, refletiu obviamente as inovações pedagógicas, tanto em suas concepções gerais como nos aspectos mais técnicos.

A arquitetura escolar da época era fruto do projeto educacional republicano, constituía-se, dessa forma, também num elemento da então propalada modernização do ensino, diante da nova ordenação do espaço, das práticas e saberes escolares. 
De acordo com Oliveira (2007), a arquitetura desses grupos escolares unia racionalidade econômica e funcionalidade a determinados padrões estéticos. Considerando a necessidade de construir rapidamente muitos edifícios para atender ao grande número de alunos, combinado ao reduzido corpo técnico e aos baixos custos, o procedimento adotado pelo Departamento de Edifícios e Obras Públicas (DOP) do Governo do Estado de São Paulo, priorizou que a construção dos edifícios escolares se pautasse pelos projetos-tipo, determinados pelo DOP que seguiam determinações governamentais. A diferenciação na execução de tais projetos, nas diferentes cidades paulistas, residia nas fachadas e ornamentação adotada, além de adequação aos perfis de terrenos.

A característica marcante da arquitetura destes projetos-tipo era a simetria da planta, a separação dos alunos por sexo: a ala masculina e a feminina, com entradas distintas e separadas internamente, sendo marcada, no exterior, por um frontão. Essas características são evidentes na imagem abaixo do Grupo Escolar Coronel Júlio César.

Figura 2 - Fachada do Grupo Escolar Coronel Júlio César

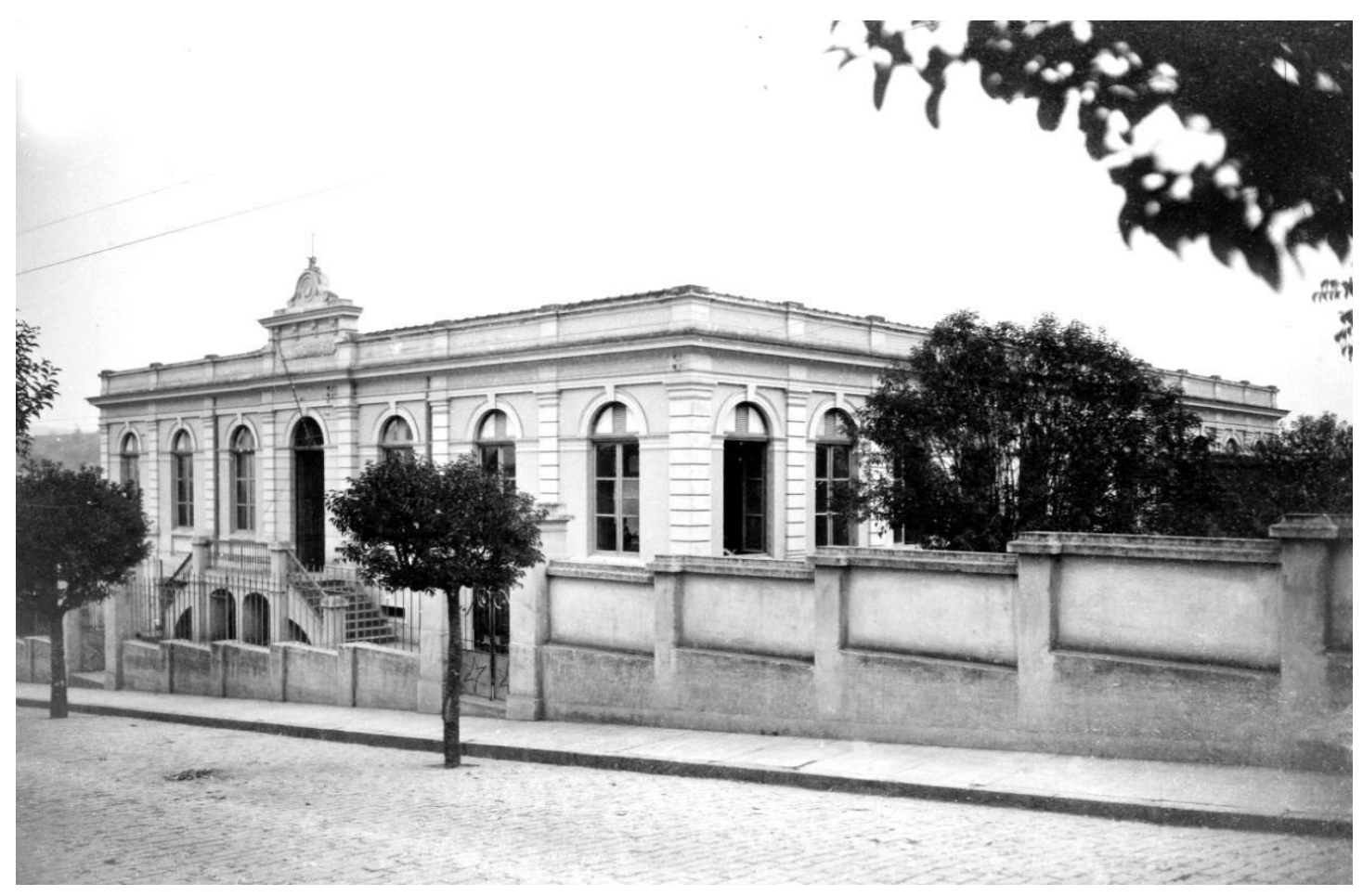

Fonte: Arquivo Histórico da E. M. E. B. "Coronel Júlio César”. 
Essa imagem visual (sem data e autoria), pertence ao Arquivo Escolar, apresenta a fachada do grupo, evidenciando a sua parte frontal por inteiro. Além disso, do ângulo que a fotografia foi produzida tem-se a impressão que o terreno é mais plano, diferentemente da imagem anterior, do Almanach de 1916.

O prédio do antigo Grupo Escolar Júlio César, foi identificado como um dos representantes da "Arquitetura Escolar Paulista da República Velha”, o que lhe garantiu ter sido tombado por determinação do CONDEPHAAT - Conselho de Defesa do Patrimônio Histórico, Arqueológico, Artístico e Turístico do Estado de São Paulo; conforme publicação do Diário Oficial do Estado de São Paulo, do dia 7 de agosto de 2002, páginas 1 e 52, sendo a Resolução de Tombamento de $\mathrm{n}^{\circ}$ 60, de 21 de julho de 2010.

Livro do Tombo Histórico: inscrição no 377, p. 103 a 110, 05/09/2011. Código Sec. Est. Educ.: 05.81.101

O Grupo Escolar Coronel Júlio César foi criado em 13 de maio de 1896 e instalado em $1^{\circ}$ de julho do mesmo ano, em imóvel alugado pela Câmara Municipal. Construído posteriormente, o atual prédio faz parte de um conjunto de projetos de autoria de José Van Humbeeck. [...]

No mesmo documento, mais adiante, pode-se ler que o prédio do grupo compõe um:

[...] conjunto de 126 escolas públicas construídas pelo Governo do Estado de São Paulo entre 1890 e 1930 que compartilham significados cultural, histórico e arquitetônico. Essas edificações expressam o caráter inovador e modelar das políticas públicas educacionais que, durante a Primeira República, reconheceram como inerente ao papel do Estado a promoção do ensino básico, dito primário, e a formação de professores bem preparados para tal função. Quanto às políticas de construção de obras públicas, são representativas pela estruturação racional de se instalar edificações adequadas ao programa pedagógico por todo o interior e capital do Estado.

O processo de restauração do grupo foi realizado no ano de 2000, pelo arquiteto Marcello Pucci. Teve como colaboradores os arquitetos Alessandra Esteves, Silvia Pannunzio, Marcelo Oliveira, Hélio Braga Júnior e o designer de perspectiva Michel Yves Seiler. A restauração desse grupo contou com a execução e pintura das paredes, o tratamento da estrutura da cobertura sem forro, revisão da rede elétrica, limpeza do piso hidráulico, pátio central da edificação, remoção do piso do pátio, execução de piso de cimento queimado, demolição da cobertura de acesso aos banheiros, demolição de alvenaria em vãos de janelas originais e execução de caixilharia em ferro, conforme 
modelo existente, demolição dos degraus das escadas e tratamento da estrutura de madeira. Foram agregadas à obra original uma escada metálica solta do edifício, uma cobertura de policarbonato e respectiva estrutura metálica. O projeto de restauração fez algumas alterações na estrutura do prédio, como é possível observar nas imagens a seguir:

Figura 3 - Projeto de restauro do Grupo Escolar Coronel Júlio César

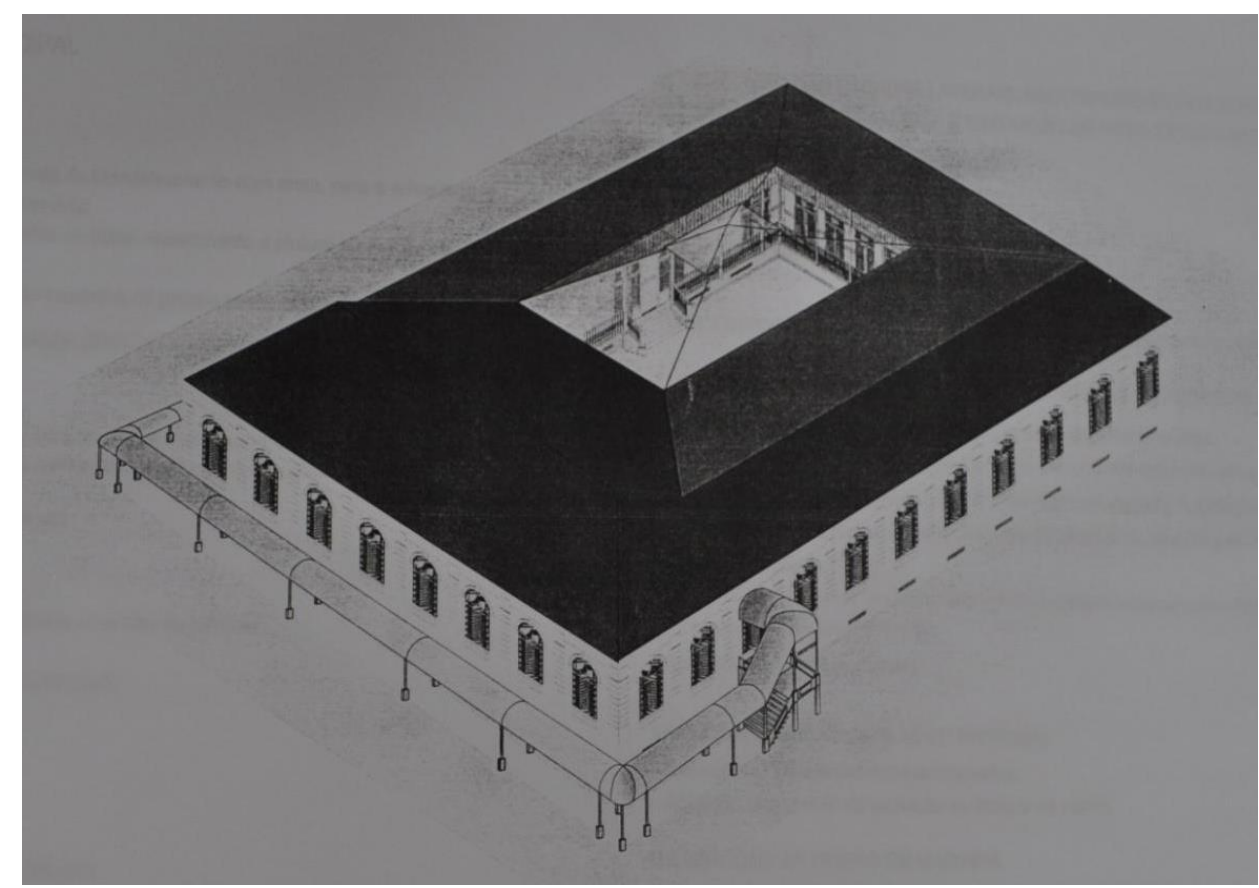

Fonte: Instituto de Recuperação do Patrimônio histórico no Estado de São Paulo. Localizado no Arquivo Histórico da E. M. E. B. "Coronel Júlio César". 
Figura 4 - : Projeto de restauro da fachada principal do Grupo Escolar Coronel Júlio César

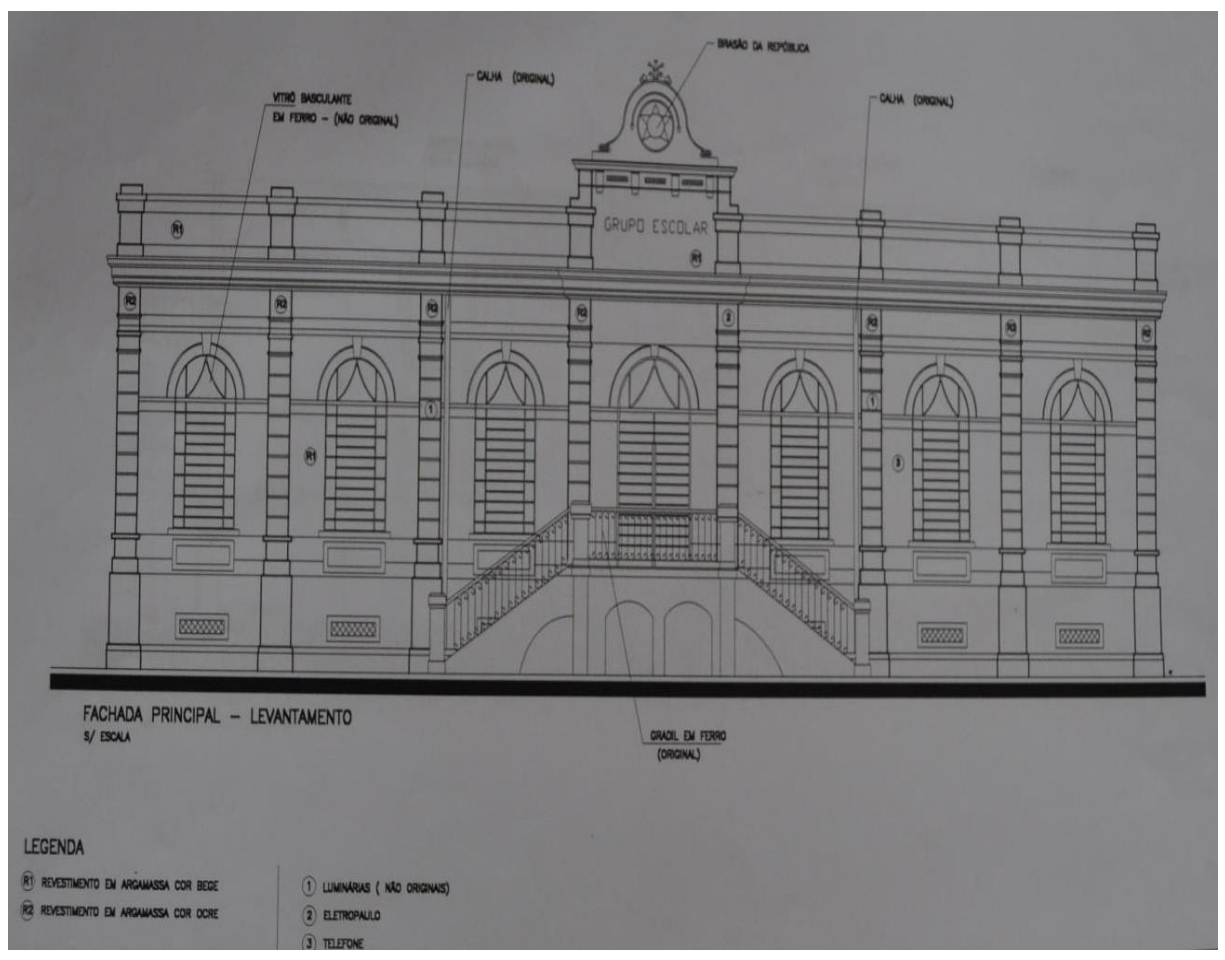

Fonte: Instituto de Recuperação do Patrimônio Histórico no Estado de São Paulo. Localizado no Arquivo Histórico da E. M. E. B. "Coronel Júlio César". Localizado no Arquivo Histórico da E. M. E. B. "Coronel Júlio César". 
Figura 5 - Restauração do grupo escolar: situação anterior e posterior ao restauro
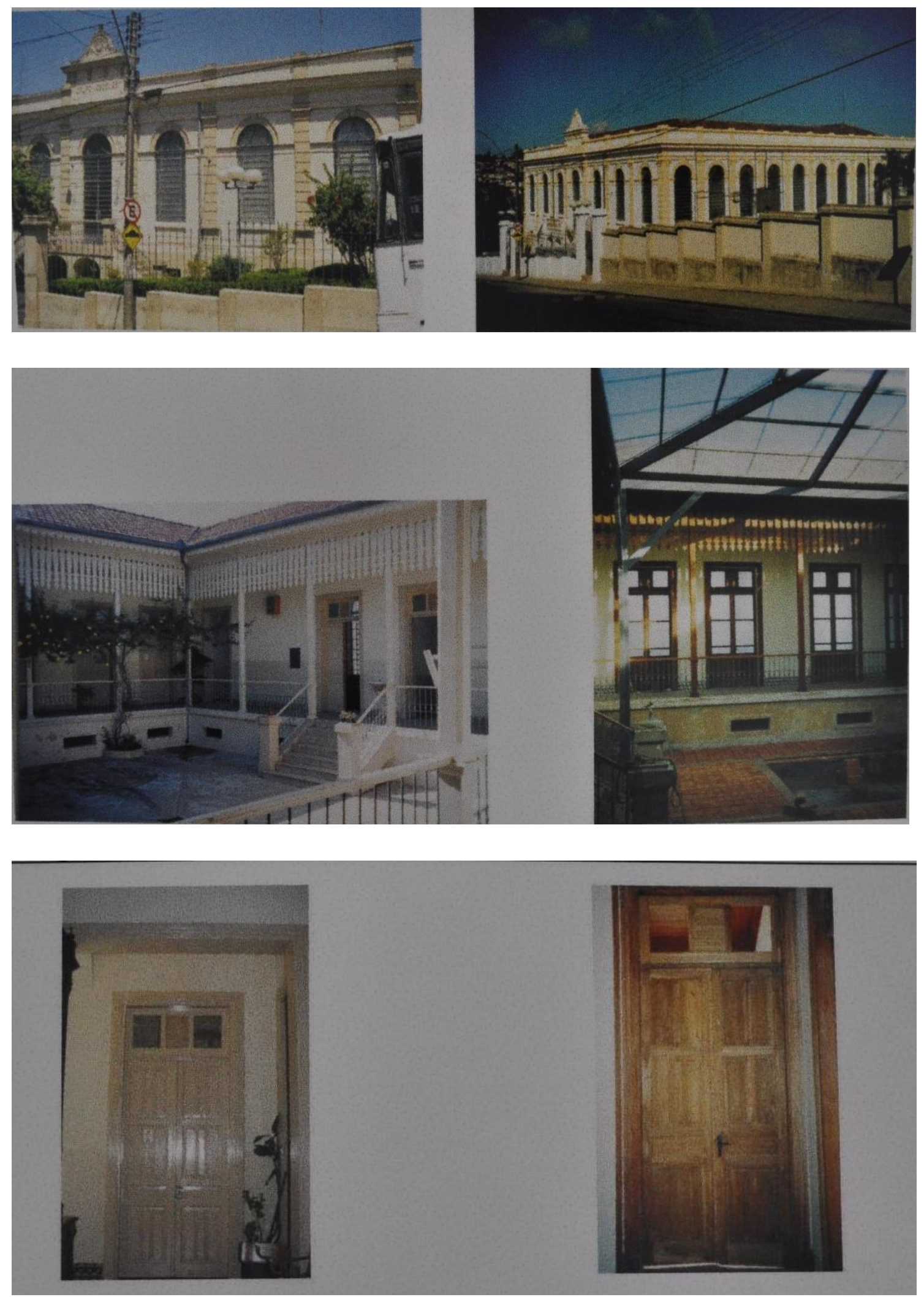

Fonte: Instituto de Recuperação do Patrimônio histórico no Estado de São Paulo.

Localizado no Arquivo Histórico da E. M. E. B. "Coronel Júlio César". 
Figura 6 - Prédio atual do Grupo Escolar Coronel Júlio César, após restauro

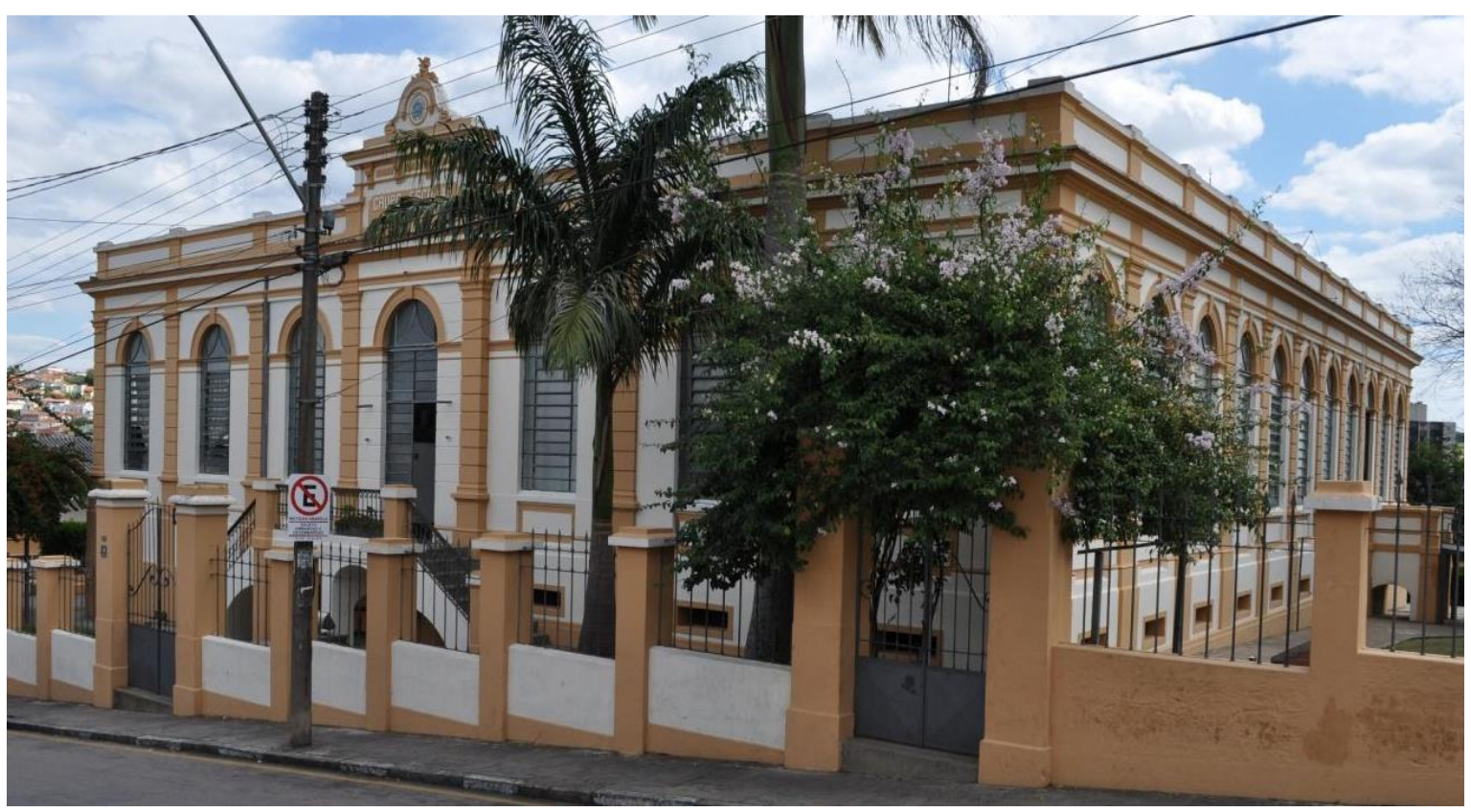

Fonte: Arquivos da autora.

Chamamos a atenção para o fato de que o próprio laudo do tombamento toma o projeto republicano paulista dos grupos escolares como referência da excelência, assim como foi aclamado na época pelos seus defensores, endossando plenamente o que foi preconizado no passado pelos republicanos paulistas - o que sinaliza a necessidade de lembrarmos de que, para além deste projeto educacional hegemônico, na época, haviam outras outras formas de educar e de pensar a educação no País; dentre as quais salientamos a existência de escolas isoladas que não adotavam o método intuitivo e nem o ensino graduado e a proposta libertária de educação.

Souza (1998, p. 91) afirma que os grupos escolares foram representantes da política republicana de valorização da escola pública graduada:

[...] dessa forma, eles conferiam a um só tempo: visibilidade à ação política do Estado e propaganda do novo regime republicano. Criar um grupo escolar tinha um significado simbólico muito maior que a criação de uma escola isolada, cuja precariedade mais se assemelhava às condições das escolas públicas do passado imperial com o qual o novo regime queria romper. Em certo sentido, o grupo escolar, pela sua arquitetura, sua organização e suas finalidades aliava-se às grandes forças míticas que compunham o imaginário social naquele período, isto é, a crença no progresso, na ciência, e na civilização. 


\section{REFERÊNCIAS}

BENCOSTTA, Marcus Levy Albino. Grupos escolares no Brasil: um novo modelo de escola primária. In: STEPHANOU, Maria; BASTOS, Maria Helena Câmara (Org.). História e memórias da educação no Brasil, 2. ed. São Paulo: Brasiliense, 1996. v. 3.

CARVAlHO, Marta Maria Chagas de. A escola e a República e outros ensaios. Bragança Paulista: EDUSF, 2003.

CORRÊA Maria Elizabeth Peirão; NEVES, Helia Maria Vendramini; MELLO, Mirela Geiger de (Org.). 1890-1920 : a arquitetura escolar paulista. 1. ed. São Paulo: FDE, 1991.

ESCOLANO, Agustín. Arquitetura como programa. Espaço-escola e currículo. In: VIÑAO FRAGO, Antonio. Currículo, espaço e subjetividade: a arquitetura escolar como programa. Rio de Janeiro: DP\&A, 2001.

FARIA FILHO, Luciano Mendes de; VIDAL, Diana Gonçalves. Os tempos e os espaços escolares no processo de institucionalização da escola primária no Brasil. Revista Brasileira de Educação, n. 14, p. 193-4, maio-ago. 2000.

GABUARDI, Lucimara Rasmussen. Itatiba na História: 1804-1959. Campinas, SP: Pontes; Itatiba, SP: Bobst Group, 2004.

ITATIBA (SP). Museu Histórico Municipal "Pe. Francisco de Paula Lima". Almanach de Itatiba. 1905. 1 jornal impresso, preto e branco.

Museu Histórico Municipal "Pe. Francisco de Paula Lima". Almanach de Itatiba. 1916. 1 jornal impresso, preto e branco.

Museu Histórico Municipal "Pe. Francisco de Paula Lima". A Reacção. 1911. 1 jornal impresso, preto e branco.

Museu Histórico Municipal "Pe. Francisco de Paula Lima". Gazeta de Itatiba. 1904. 1 jornal impresso, preto e branco.

MARQUES, Juliano Ricardo. Jundiaí, um impasse regional - o papel de Jundiaí entre duas regiões metropolitanas: Campinas e São Paulo. 2008. 178 f. Dissertação (Mestrado) - Faculdade de Filosofia, Letras e Ciências Humanas, Universidade de São Paulo, São Paulo, 2008.

NAVARRA, Wanda Silveira. O uso da terra em Itatiba e Morungaba. 1977. f. Tese (Doutorado) - Universidade de São Paulo, São Paulo, 1977.

OLIVEIRA, Fabiana Valeck de. Arquitetura escolar paulista nos anos 30. 2007. 140 f. Dissertação (Mestrado) - Faculdade de Arquitetura e Urbanismo, Universidade de São Paulo, São Paulo, 2007.

SANGIORGI, Diloca Ferraz. Conheça sua cidade: um pouco da história de Itatiba. São Paulo: Vanguarda, 1969. 
SEVCENKO, Nicolau. O prelúdio republicano, astúcias da ordem e ilusões do progresso. In: SEVCENKO (Org.). História da vida privada no Brasil. São Paulo: Companhia das Letras, 1998.

SOUZA, Rosa Fátima de. Templos de civilização. São Paulo: Ed. UNESP, 1998.

VENDRAMIN, Melissa Toffani Magalhães. Os primórdios da educação em Itatiba, SP, 1830-1930: imagens locais e fontes educacionais. 169 f. 2009. Dissertação (Mestrado em Educação) - Faculdade de Educação, Universidade Estadual de Campinas, Campinas, 2009.

VIDAL, D. G. ; FARIA FILHO, L. M. As lentes da história: estudos de história e historiografia da educação no Brasil. Campinas, SP: Autores Associados, 2000.

VINÃO FRAGO, Antonio; ESCOLANO, Agustín. Currículo, espaço e subjetividade: arquitetura como programa. 2. ed. Tradução de Alfredo Veiga Neto. Rio de Janeiro: DP\&A, 2001.

\section{SITES}

A Cidade de Itatiba. História. Prefeitura Municipal de Itatiba. Disponível em: <http://www.itatiba.sp.gov.br/acidade/historia>. Acesso em: 20 out. 2014.

Processo de tombamento. Disponível em: <http://www.cultura.sp.gov.br/ portal/site/SE C/menuitem.bb3205c597b9e36c3664eb10e2308ca0/?vgnextoid=91b6ffbae7ac1210Vgn VCM1000002e03c80aRCRD\&Id=b88c91cc051e4410VgnVCM1000008936c80a > Acesso em: 6 nov. 2015.

\section{Recebido em: 15/10/2021}

Aprovado em: 20/11/2021 